\title{
Education in Circular Economy: Focusing on Life Cycle Thinking at the University of the Basque Country
}

\author{
Rikardo Minguez $^{(凶)}$, Erlantz Lizundia, Maider Iturrondobeitia, Ortzi Akizu-Gardoki, \\ and Estibaliz Saez-de-Camara \\ University of the Basque Country UPV/EHU, Bilbao, Spain \\ rikardo.minguez@ehu. eus
}

\begin{abstract}
Since 2002, the University of the Basque Country (UPV/EHU) has supported several teaching experiences related to the so-called Life Cycle Thinking or Ecodesign in collaboration with local Institutions. The kick off was the Ecodesign Learning Center aiming to promote environmental education at the Faculty of Engineering in Bilbao. In this framework, the last effort has been the implementation of a Master's Degree entitled Circular Economy: Business Application. This course has been successfully implemented in the 2019-2020 academic year and has been specifically designed to provide training in circular economy for people with backgrounds as varied as product manufacturing engineering, environmental engineering or economics. These studies are aimed to become a European reference in its goal of promoting circular economy, life cycle thinking, ecodesign and sustainable development. This paper analyzes the learning issues and characteristics of this Master's degree placing a special emphasis on its novel competencies and learning outcomes for our society. It can be concluded that the Master's degree is a pioneering teaching experience, being the forefront of Circular Economy Education in Southwestern Europe.
\end{abstract}

Keywords: Environmental education - Life cycle thinking teaching experience · Circular economy $\cdot$ Life cycle assessment

\section{Introduction}

Besides the world health pandemic crisis we are enduring in spring 2020, our planet lives in an environmental crisis, with alarming social and economic inequalities, increasing rates of loss of natural and cultural biodiversity, and a senseless growing pressure on natural resources and systems.

In this context, since the end of the decade of the 80s, aware of the necessity for a deep change, the concept of sustainability has been strengthened. At the same time, it seems to have become a multipurpose and valid term for any context, objective, argumentation or ideological-political current [1].

Currently the United Nations's Global Action Programme on Education for Sustainable Development (ESD) [2] aims to contribute substantially to the 2030 development agenda, through two objectives: 
- Reorienting education and learning so that everyone has the opportunity to acquire the knowledge, skills, values and attitudes that empower them to contribute to a sustainable future.

- Strengthening education and learning in all agendas, programmes and activities that promote sustainable development.

In parallel with this, the European Commission has proclaimed the European Green Deal [3] which constitutes a new growth strategy aiming to transform the European Union (EU) into a fair and prosperous society, with a modern, resource-efficient and competitive economy with no net emissions of greenhouse gases by 2050 and where the economic growth remains decoupled from resource use.

At regional level, the government of the Basque Autonomous Community strongly supports EDS in higher education by means of the Agenda Euskadi - Basque Country 2030 [4]. The two main objectives of the program are to encourage the market to act in the interest of the environment, and to promote ESD in higher education in coordination with the United Nations's Global Action Programme. In January 2020, the Basque Government has made public the keys of the circular economy strategy 2030 [5], with many strategic objectives and challenges, among others promoting degree studies and research at university level.

Aligned with all these policies, the University of the Basque Country (UPV/EHU) has supported different teaching experiences related to the so-called Life Cycle Thinking or Ecodesign in collaboration with some local Institutions.

The kick off for these experiences was established in 2002 with the foundation of the Ecodesign Learning Center at the Faculty of Engineering in Bilbao [6]. More recently, these efforts have been focused on the implementation of a new Master's Degree entitled Circular Economy: Business Application, which is going to be described in the following chapters, with especial emphasis on the aspects related to ecodesign and life cycle thinking [7].

\section{Origin of the Master Degree in Circular Economy}

The Basque Ecodesign Center [8] is a partnership framework between firms in the private sector and the Basque Government. It aims to foster the design and execution of innovative ecodesign projects. Ihobe [9] is a publicly-owned company under the auspices of the Basque Government's Ministry for the Environment, Territorial Planning and Housing. Ihobe supports the Basque Government in the implementation of its environmental policy and in the spreading of the environmental sustainability culture in the Basque Autonomous Community.

Boosted by Ihobe, the Basque Ecodesign Center and the Sustainability directorate of the University of the Basque Country, in October 2019 the university launched the first edition of the postgraduate course entitled Circular Economy: Business Application (consisting of 36 ECTS) and for the next academic year a new master degree with 60 ECTS is on its way.

The European studies that have inspired and served as a reference for the Master's Degree proposal have been the CIRCLE programme [10], which is an Erasmus Mundus 
International Master's Programme on Circular Economy, with several labeled master programmes certified by the EIT (European Institute of Innovation and Technology) [11].

\section{Facts of the Master Degree in Circular Economy}

The Master's Degree in Circular Economy is projected to begin teaching during September 2020 and to finish these lectures on June 2021 (Table 1). The Master's Thesis to complete the 60 ECTS necessary to obtain the degree, is expected to be defended on September 2021.

The maximum number of students has been fixed to 25 and more than 35 lecturers and professionals from the industrial sector will take part in it. Student candidates will be sought among engineers and economists working in local industry, service companies or public administration. Subjects will be taught at the Faculty of Engineering and the Faculty of Economics and Business in Bilbao.

Table 1. Subjects of the Master Degree in Circular Economy for the 2020-2021 academic year.

\begin{tabular}{c|l|c}
\hline & Subject & ECTS \\
\hline 1 & Circular Economy: General Context & 6 \\
\hline 2 & $\begin{array}{l}\text { Eco-innovation as a Business Opportunity. Regulatory Framework and } \\
\text { Concept }\end{array}$ & 3 \\
\hline 3 & $\begin{array}{l}\text { Environmental Impacts Derived from the Production-consumption of } \\
\text { Products and Services }\end{array}$ & 3 \\
\hline 4 & Environmental Management Tools in the Company & 3 \\
\hline 5 & Ecodesign and Circular Economy & 3 \\
\hline 6 & Life Cycle Thinking 1: Tools for Calculation and Communication & 3 \\
\hline 7 & Life Cycle Thinking 2: Quantification of the Product Environmental Footprint & 3 \\
\hline 8 & $\begin{array}{l}\text { Circular Economy in the Company: From Ecodesign to Product } \\
\text { Commercialization }\end{array}$ & 6 \\
\hline 9 & $\begin{array}{l}\text { Circular Economy in the Company: Sustainable Entrepreneurship, Business } \\
\text { Models in Circular Economy }\end{array}$ & 3 \\
\hline 10 & Circular Economy Initiatives. Business Cases & 9 \\
\hline 11 & Practical Workshops on Circular Economy & 6 \\
\hline 12 & Master's Thesis & 12 \\
\hline
\end{tabular}

\subsection{Life Cycle Thinking: Ecodesign and Life Cycle Assessment}

The subjects closely related to Life Cycle Thinking make up 9 ECTS divided into 3 subjects consisting of 3 ECTS: 


\section{Ecodesign and Circular Economy.}

1. Introduction to the concept of ecodesign: basic principles and implications for the design of products and services.

2. Standards in ecodesign.

3. Ecodesign methodology.

4. Ecodesign and companies: Integration of the Ecodesign in the enterprise management systems. Product-service systems.

\section{Life Cycle Thinking 1: Tools for Calculation and Communication.}

1. Product life cycle: background and concepts. Life cycle and extended producer responsibility. Implications for the product designer.

2. Methodological principles of Life Cycle Analysis based on international standards. Life Cycle Assessment Software: Open LCA and SIMAPRO.

3. Communication and marketing with a Life Cycle approach.

\section{Life Cycle Thinking 2: Quantification of the Product Environmental Footprint.}

1. Social and environmental impacts.

2. Calculation of the environmental footprint of products and organizations. Combination of Life Cycle Assessment tools and Input-Output sector tables. Global Multi Regional Input-Output methodology (GMRIO).

3. Sustainable Product Design Tools. Product design cycle for a circular economy.

4. The R's principles in Circular Economy. Reuse, Repair or Recycle + Restructure, Revalue, Relocate and Reconceptualize.

Overall, emphasis is made on how ecodesign serves to reduce the environmental impacts associated with a product along its whole life cycle. The relevance of servitization as a more sustainable new business model is also shown. Within an ecodesign framework, the methodology for LCA is thoroughly shown using different software. To get further knowledge, the calculation of different footprints is also shown. All this would enable the students to get a wide and deep overview on the Environmentally Conscious Design concept.

\section{Specific Learning Outcomes or Competencies}

When drawing up the Master's programme, the aim was to ensure that the students become experts in the challenges that the new circular economy poses for local companies. Consequently, the most relevant specific competencies (knowledge, skills, and attitudes) that students must have acquired at the end of their Master's studies are the following:

- To define the concepts of Circular Economy, Sustainable Economy, Low Carbon Economy and Eco-Innovation.

- To understand and explain the changes involved in the transition from a linear to a circular type of economy, as well as to recognize the opportunity they represent.

- To identify the current applicable environmental regulations (air, water, waste and soil) in order to carry out proper environmental management in the company.

- To define the concept of eco-design and to become aware of the environmental, economic and social implications of product design. 
- To apply the ecodesign methodology and manage the tools available for ecodesign in the industrial field

- To define the concept of life cycle and identify the phases of the life cycle of a product, as well as list the regulations of the Life Cycle Analysis.

- To know and apply the evaluation methodologies and software tools for product life cycle analysis.

- To formulate guidelines for communication and marketing with a life cycle approach.

- To define and understand corporate and competitive strategies to integrate the environmental variable in the company and select the most appropriate strategy for each particular case.

- To identify business opportunities in the field of the Circular Economy for different sectors, stakeholders and design proposals.

These competencies are fully aligned with those proposed by some European universities that are considered to be at the leading edge in this area of knowledge and education [12-14]. The Master's degree covers the proposed seven circular economy competencies for design to a greater or lesser extent: Circular Impact Assessment, Design for Recovery, Design for Multiple Use Cycles, Circular Business Models, Circular User Engagement, Circular Economy Collaboration, and Circular Economy Communication.

\section{Conclusions}

It can be concluded that postgraduate studies in Circular Economy are an ongoing reality at the University of the Basque Country.

Furthermore, these studies are ambitious and highly developed in the fields of Ecodesign and Life Cycle Thinking. It is thus expected that the graduated students will help advancing towards a sustainable society as they are incorporated into academia or industry. This would enable not only a more efficient integration of the circular economy concepts into our community but also may allow enterprises to get ahead of the many legislative changes that are expected to occur in the near future.

The initiative is pioneering in Southwestern Europe and in the near future alliances will be sought with other European universities to offer a joint degree or at least to be able to offer mobility to students so that they can experience other academic realities.

Acknowledgments. The authors would like to thank Ihobe and the Basque Ecodesign Center for promoting economically and technically the Master Degree in Circular Economy: Business Application in the Faculty of Engineering in Bilbao.

\section{References}

1. McGregor, S.L.T.: Alternative Communications about Sustainability Education. Sustainability, vol. 5, p. 3562 (2013) 
2. UNESCO (United Nations Educational, Scientific and Cultural Organization). Education for Sustainable Development Goals: Learning Objectives; UNESCO: Paris, France (2017)

3. https://ec.europa.eu/info/files/communication-european-green-deal_en. Accessed 4 May 2020

4. https://www.euskadi.eus/pdf/agenda-euskadi-basque-country-2030.pdf. Accessed 4 May 2020. (in Spanish)

5. https://www.ihobe.eus/publications/the-keys-of-the-circular-economy-strategy-of-the-bas que-country-2030-draft. Accessed 4 May 2020

6. Prado-Trigo, A., et al.: Eco-design classrooms project: life cycle assessment and eco-design in Basque industry. Dyn. Spain 86(1), 74-79 (2011)

7. https://www.ehu.eus/es/web/graduondokoak/master-economia-circular-aplicacion-empresa. Accessed 4 May 2020. (in Spanish)

8. https://www.basqueecodesigncenter.net. Accessed 4 May 2020

9. https://www.ihobe.eus/home. Accessed 4 May 2020

10. https://www.jointdegree.eu/de/circle-erasmus-mundus-international-masters-programmeon-circular-economy/. Accessed 4 May 2020

11. https://eitrawmaterials.eu/eit-rm-academy/labelled-masters/. Accessed 4 May 2020

12. Lambrechts, W., et al.: The role of individual sustainability competences in eco-design building projects. J. Clean. Prod. 208, 1631-1641 (2019)

13. Sumter, D., et al.: Circular economy competencies for design. Sustainability 12, 1561 (2020)

14. Korhonen, J., et al.: Circular economy: the concept and its limitations. Ecol. Econ. 143, 37-46 (2018)

Open Access This chapter is licensed under the terms of the Creative Commons Attribution 4.0 International License (http://creativecommons.org/licenses/by/4.0/), which permits use, sharing, adaptation, distribution and reproduction in any medium or format, as long as you give appropriate credit to the original author(s) and the source, provide a link to the Creative Commons license and indicate if changes were made.

The images or other third party material in this chapter are included in the chapter's Creative Commons license, unless indicated otherwise in a credit line to the material. If material is not included in the chapter's Creative Commons license and your intended use is not permitted by statutory regulation or exceeds the permitted use, you will need to obtain permission directly from the copyright holder.

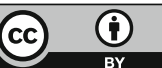

